\title{
The effect of a direct payment or a lottery on questionnaire response rates: a randomised controlled trial
}

\author{
Paula-J Roberts, Chris Roberts, Bonnie Sibbald, David J Torgerson
}

Seven Brooks Medical Centre, 21 Church Street, Atherton M46 9DE

P-J Roberts

\section{University of} Manchester, Oxford Road, Manchester C Roberts

National Primary Care Research and Development Centre, Williamson Building, University of

Manchester, Oxford Road, Manchester B Sibbald

Department of Health Studies and Centre for Health Economics, University of York, York

D J Torgerson

Correspondence to: Dr P-J Roberts

Accepted for publication 10 July 1999
Postal questionnaires are frequently used in research. One way of improving response rates is to use lotteries, although the evidence for their effectiveness is equivocal. ${ }^{1-4}$ An alternative, or complementary, approach to using lotteries is to make direct payments to survey responders. Few trials have evaluated direct payment compared with lotteries. ${ }^{3}$

\section{Methods}

Questionnaires about menopause services in the North West of England were sent to a random sample of 1000 women aged 40 to 65 during September to November 1997. The questionnaires included questions about use of hormone replacement therapy (HRT) and women's demographic characteristics.

The sample of women were randomised in a $2 \times 2$ factorial trial to estimate the effectiveness of the two forms of incentive and their potential interaction within a single study. Unequal randomisation of 3 to 1 favouring no direct payment was used to minimise research costs, which led to unequal numbers in each of the four arms of the study (lottery alone, $n=375$; direct payment alone, $\mathrm{n}=125$; lottery and direct payment, $\mathrm{n}=125$; no lottery and no direct payment, $\mathrm{n}=375$ ). The direct payment consisted of $£ 5$ for each respondent while the lottery was for a prize draw of $£ 50$. Payment and/or inclusion in the prize draw were made on receipt of a completed questionnaire unless declined by respondents.

Non-responders were sent up to two further mailings approximately one month apart. Women returning a blank questionnaire were not sent further mailings. To comply with the Data Protection Act, a Health Authority custodian attended with names and addresses for the three mailings. The investigators therefore had no information about the characteristics of non-responders.

Analysis was by means of logistic regression using the SPSS statistical package.

\section{Results}

After three mailings 587 completed questionnaires were returned. Two questionnaires were returned by the post office as not being known at the address and these were removed from the analysis. The mean age of respondents was 51 range $40-65,91 \%$ had one or more children and the mean number of children was 2.2 .

Table 1 shows the proportions of patients responding by study groups and the odds that financial incentives increased response when compared with non-payment. There was no interaction between lottery and payment $(p=0.78)$ so it was possible to examine the effect of each intervention independently. Direct payments significantly increased the odds of response (odds ratio $=1.70,95 \%$ CI 1.11 to $2.60, \mathrm{p}=0.013)$. The lottery did not

Table 1 Response rates by study group and multivariate analysis

\begin{tabular}{|c|c|c|c|c|c|c|c|}
\hline Group & Control $(n=374)$ & Lottery $(n=374)$ & $\begin{array}{l}\text { Pooled non-payment } \\
(n=748) \text { Cost per } \\
\text { sampled woman } \\
\text { (cost per response) } \neq\end{array}$ & $\begin{array}{l}\text { Payment } \\
(n=125)\end{array}$ & $\begin{array}{l}\text { Lottery and } \\
\text { payment }(n=125)\end{array}$ & $\begin{array}{l}\text { Pooled payment } \\
(n=250) \text { Cost per } \\
\text { sampled woman } \\
\text { (cost per response)\& }\end{array}$ & $\begin{array}{l}\text { Marginal cost per } \\
\text { completed response of } \\
\text { payment compared } \\
\text { with non-payment }\end{array}$ \\
\hline \multicolumn{8}{|l|}{ Response rate } \\
\hline Initial mailing & $37.7 \%(141 / 374)$ & $41.7 \%(156 / 374)$ & $\begin{array}{l}39.7 \% \\
£ 1.70(£ 4.28)\end{array}$ & $45.6 \%(57 / 125)$ & $49.6 \%(62 / 125)^{\star}$ & $\begin{array}{l}47.6 \% \\
£ 3.50 \dagger(£ 7.35)\end{array}$ & $\begin{array}{l}7.9 \% \\
£ 1.80(£ 22.78)\end{array}$ \\
\hline 1st reminder & $20.4 \%(38 / 186)^{\star}$ & $21.0 \%(39 / 186)^{\star}$ & $\begin{array}{l}20.7 \% \\
£ 1.70(£ 8.21)\end{array}$ & $22.0 \%(13 / 59)^{\star}$ & $31.7 \%(19 / 60)^{\star}$ & $\begin{array}{l}26.9 \% \\
£ 3.05(£ 11.34)\end{array}$ & $\begin{array}{l}6.2 \% \\
£ 1.35(£ 21.77)\end{array}$ \\
\hline 2nd reminder & $17.6 \%(22 / 125)^{\star}$ & $18.8 \%(24 / 128)^{\star}$ & $\begin{array}{l}18.2 \% \\
£ 1.70(£ 9.34)\end{array}$ & $29.6 \%(13 / 44)^{\star}$ & $14.3 \%(5 / 35)^{\star}$ & $\begin{array}{l}22.8 \% \\
£ 2.84(£ 12.46)\end{array}$ & $\begin{array}{l}4.6 \% \\
£ 1.14(£ 24.78)\end{array}$ \\
\hline Total & $53.7 \%(201 / 374)$ & $58.6 \%(219 / 374)$ & $\begin{array}{l}56.1 \% \\
£ 3.12(£ 5.56)\end{array}$ & $66.4 \%(83 / 125)$ & $68.8 \%(86 / 125)$ & $\begin{array}{l}67.6 \% \\
£ 5.85(£ 8.65)\end{array}$ & $\begin{array}{l}11.5 \% \\
£ 2.73(£ 23.74)\end{array}$ \\
\hline \multicolumn{8}{|c|}{ Logistic regression analysis modelling of response by incentive method } \\
\hline Variable & & Coefficient $(\beta)$ & Odds ratios $(95 \%$ CI) & $\chi_{1}^{2}$ & $p$ Value & & \\
\hline Payment & & 0.53 & $1.70(1.11$ to 2.60$)$ & 6.23 & 0.013 & & \\
\hline Lottery & & 0.20 & $1.22(0.91$ to 1.62$)$ & 1.76 & 0.185 & & \\
\hline Payment-lotter & interaction & -0.09 & $0.92(0.50$ to 1.68$)$ & 0.08 & 0.780 & & \\
\hline Constant & & 0.15 & & & & & \\
\hline
\end{tabular}

${ }^{\star}$ Subjects returning a blank form received no further reminders so that the denominator for reminder response rates are smaller than the numbers not responding to the previous mailing. †Assumes 29 women did not accept payment therefore costs are based on payment to 90 women not 119 . $¥$ The cost per completed response in the pooled non-payment column was calculated by dividing the cost of the questionnaire $(£ 1.70)$ by the proportion responding, for example, $£ 1.70 / 0.397=£ 4.28$. The total cost per sampled woman was the total cost of questionnaires divided by women sampled $(£ 2334.10 / 748)$ and the final cost per respondent by dividing the total cost by the number of responders $(£ 2334.10 / 420)$. \$The cost per sampled woman was calculated by adding the total cost of questionnaires sent to the cost of 90 respondents who accepted payment divided by the number of women sampled, for example, $(£ 1.70 \times 250)+(£ 5 \times 90) / 250$. The cost per response was calculated by dividing the cost by the number of respondents, for example, $(£ 1.70 \times 250)+(£ 5 \times 90) / 119$. The total cost per sampled woman was the total cost of questionnaires divided by women sampled $(£ 1461.60 / 250)$ and the final cost per respondent was the total cost divided by the number of responders $(£ 1461.60 / 169)$. TThe marginal cost per completed response of payment compared with non-payment was calculated from the difference in response rates and costs from the pooled non-payment and pooled payment columns, for example, the total marginal cost was $(£ 5.85-£ 3.12) /(0.676-0.561)$. 
significantly increase response rates (odds ratio $=1.22,95 \%$ CI 0.91 to $1.62, \mathrm{p}=0.19$ ).

After pooling the lottery and non-payment groups, the response rate was $67.6 \%$ in the payment group compared with $56.1 \%$ in the non-payment group (diff $=11.5 \%, 95 \%$ CI $4.7 \%$ to $18.3 \%$ ). $83 \%$ (140 of 169 ) of respondents completing questionnaires accepted payment, 29 respondents declined payment. Table 1 shows the cost per sampled woman and the marginal cost per completed response. The means by which the these costs were calculated is explained in the footnotes.

There were no differences between the direct payment and non-payment groups in mean age (diff $=-0.6,95 \% \mathrm{CI}-1.8$ to 0.6 years, $\mathrm{p}=$ 0.32 ) or level of educational qualifications (Mann-Whitney $\mathrm{U}$ test $\mathrm{p}=0.83$ ). The direct payment group had lower ever HRT use compared with the non-payment group (diff = $8.5 \%, 95 \% \mathrm{CI}$ of difference 0.0 to $16.9 \%, \mathrm{p}=$ 0.056).

\section{Comment}

The use of a $£ 5$ direct payment incentive increases absolute response rates by $12 \%$. However, like other studies, a lottery did not significantly increase response rates. ${ }^{14}$ The marginal cost per extra response using a $£ 5$ incentive was four times that of the control group. Whether this extra cost is worthwhile may depend upon whether increasing response rates leads to a more representative sample. In this study, more non-users of HRT responded to payment suggesting that payment had a larger impact among women for whom the questionnaire had a lower interest (that is, non-users of HRT).

It seems that direct payments may be more effective than lotteries and payment may preferentially increase response rates among women with least interest in the subject of the survey. These findings were obtained in middle aged women and may not apply to other populations.

Funding: NHS NorthWest Region Research Practices Initiative. Conflicts of interest: none.

\footnotetext{
1 Brown AP, Lawrie HE, Kennedy AD, et al. Cost effectiveness of a prize draw on response to a postal questionnaire: results of a randomised trial among orthopaedic outpatients in Edinburgh. $f$ Epidemiol Community Health 1997;51:463-4.

2 SpryVM, Hovell MF, Sallis JG, et al. Recruiting survey respondents to mailed surveys: Controlled trials of respondents to mailed surveys: Controlled trials of
incentives and prompts. Am $\mathcal{F}$ Epidemiol 1989;130:166-72.

3 Marrett LD, Kreiger N, Dodds L, et al. The effect on response rates of offering a small incentive with a mailed questionnaire. Ann Epidemiol 1992;2:745-53.

4 Mortagy AK, Howell JBL, Waters WE. A useless raffle. $\mathcal{f}$ Epidemiol Community Health 1985;39:183-4.
} 